\title{
Effect of L-Carnitine Supplementation on Cardiac Carnitine Palmitoyltransferase Activities and Plasma Carnitine Concentrations in Adriamycin-Treated Rats
}

\author{
HYE-RAN YOON, YOUNG MI HONG, RICHARD L. BORIACK, AND MICHAEL J. BENNETT \\ Metabolic Disease Detection Laboratory, Seoul Medical Science Institute, Seoul, Korea [H.R.Y.]; \\ Department of Pediatrics, College of Medicine, Ewha Woman's University, Seoul, Korea [Y.M.H.]; and \\ Department of Pathology and Pediatrics, University of Texas Southwestern Medical Center at Dallas, \\ Texas, U.S.A. [R.L.B., M.J.B.]
}

\begin{abstract}
Adriamycin (ADR) inhibits the carnitine palmitoyl transferase (CPT) system and consequently the transport of longchain fatty acids across mitochondrial membranes. L-Carnitine (CARN) plays a major role in fatty acid oxidation by translocating activated long-chain fatty acids into the matrix of mitochondria. CARN has been shown to be of benefit in certain cardiac conditions including cardiomyopathy and myocardial infarction. This study was devised to investigate the effect of CARN on altered CPT I and CPT II activity in the cardiomyopathy associated with ADR therapy. We also assessed the effect of CARN on the plasma free, total, and acylcarnitine concentrations. Four groups, each consisting of four male Sprague-Dawley rats, were studied: group $1(n=4)$ was not given either ADR or CARN; group $2(n=4)$ was given ADR ( 15 and $20 \mathrm{mg} / \mathrm{kg}$, respectively, cumulative dose) by i.p. injections for 1 and $2 \mathrm{wk}$; group 3 ( $n=$ 4) was given the same dose of ADR with CARN (200 mg/kg); and group $4(n=4)$ was given CARN $(200 \mathrm{mg} / \mathrm{kg})$. The activities of CPT I and CPT II in heart were significantly decreased in the ADR-treated rats $(p<0.05)$ in a dose-dependent
\end{abstract}

\section{ABSTRACT}

manner. The reduced activities of CPT I and CPT II, inhibited by ADR, were not normalized by supplementation with CARN $(p<$ 0.05). In rats supplemented with CARN alone, the activities of CPT I and CPT II were elevated approximately $50 \%$ above those of the control rats $(p<0.05)$. ADR treatment resulted in elevation of plasma free and total CARN concentrations $(p<$ 0.05). Supplementation with CARN did not effect the increased plasma CARN concentrations resulting from ADR treatment ( $p$ $<0.05)$. This study supports the concept that ADR toxicity results from the inhibition of both CPT I and CPT II activities and that one of the causes of ADR-induced cardiomyopathy is a result of globally impaired fatty acid oxidation. (Pediatr Res 53: 788-792, 2003)
ADR, adriamycin
Abbreviations
CARN, L-carnitine
CPT, carnitine palmitoyltransferase

The precise mechanism for the pathogenesis in ADRinduced cardiomyopathy has not been elucidated $(1,2)$. A number of different hypotheses have been proposed to account for the cardiotoxic effect of ADR. These include the production of free radical species $(3,4)$, leading to lipid peroxidation of cardiac microsomal membranes (5), the differential accumulation and retention of positively charged ADR as a result of high negative membrane potential (6), an interaction with nucleic

Received December 13, 2001; accepted November 14, 2002.

Correspondence: Young Mi Hong, M.D., Ph.D., Department of Pediatrics, Ewha Womans University Hospital, 70, Chongro- 6- Ka, Chongro-Ku, Seoul 110-126, Korea; e-mail: hongym@chollian.net

Supported in part by a grant from the Ministry of Public Health and Welfare, South Korea (HMP-00-B-21000-0033 and HMP-98-E-1-0004).

DOI: 10.1203/01.PDR.0000057988.62605.13 acid or nuclear components (7), and disruption of a cardiacspecific program of gene expression (8). Increased myocardial lipid accumulation and plasma lipid levels are usually associated with ADR-induced cardiomyopathy (9).

It has been suggested that ADR may exert at least part of its cardiotoxicity by inhibition of fatty acid oxidation in the heart (10-14). Impaired cardiac fatty acid oxidation is usually associated with diastolic dysfunction (15), cardiomyopathy, and congestive heart failure as a result of a deficiency in energy supply and possible accumulation of toxic intermediates of fatty acid oxidation in cardiac tissues (16).

Two CPT activities exist within mitochondria; CPT I and CPT II are located in the outer and inner mitochondrial membranes, respectively. Both the outer and inner membrane CPT activities have been reported to be inhibited by ADR, although 
the degree of inhibition of CPT I and CPT II remains controversial $(17,18)$. Brady and Brady (17) suggested that CPT I was less sensitive to the inhibition by ADR than CPT II because of the lower cardiolipin content in the outer mitochondrial membrane. Kashfi et al. (18) demonstrated inhibition of CPT I and CPT II by ADR in isolated heart and liver mitochondria but reported that the outer membrane CPT I was more sensitive to inhibition by ADR than the inner membrane CPT II.

CARN, an important cofactor for the translocation of fatty acids into the mitochondria for $\beta$-oxidation, has been shown to partially protect the myocardium against ADR-induced cardiotoxicity without interfering with its antitumor activities (13).

We report here the results of an investigation on the effects of CARN on CPT activities in hearts from ADR-treated rats and its effects on the free and total CARN levels in plasma.

\section{METHODS}

Animals. Male Sprague-Dawley rats, weighing 250-300 g, were purchased from Korean Laboratory Animal Center (Chungbuk Province, Korea). Rats were allowed free access to standard diet essentially free from CARN derivatives and water ad libitum. The Seoul National University's Institutional Care and Animal Use Committee approved the animal protocol.

ADR-induced cardiomyopathy protocol. The rats were divided into four groups. Group 1, controls, was not given ADR or CARN. Group 2 was given ADR (15 and $20 \mathrm{mg} / \mathrm{kg}$, respectively, cumulative dose) by two and four i.p. injections for 1 and 2 wk. Group 3 was given the same dose of ADR and supplemented with CARN (200 mg/kg). Group 4 was given CARN (200 mg/kg). Cardiomyopathy was induced in groups 2 and 3 by i.p. injection of ADR hydrochloride (doxorubicin hydrochloride, cumulative dose, 5, 10, 15, and $20 \mathrm{mg} / \mathrm{kg}$ ) for a 2-wk period. CARN (200 mg/kg) was administered by i.p. injection daily for a 2 -wk period. The volume of ADR injected was $1.25 \mathrm{~mL} / \mathrm{kg}$, and that of CARN, $1 \mathrm{~mL} / \mathrm{kg}$. The rats were weighed and observed for general appearance, behavior, and mortality during the study period. They were also assessed for clinical evidence of ascites, limb edema, and abnormal fur characteristics at the time of each injection and before sacrificing. At the toxic dose of ADR (15 and $20 \mathrm{mg} / \mathrm{kg}$ ), congestive heart failure was seen in affected rats with notable tachypnea and ascites. Increased heart weight and internal ventricular dimensions were demonstrated at autopsy. Irregularly arranged myofibrils, markedly swollen mitochondria, nuclear fragmentation, and chromatin clumping were found by electron microscopy, and apoptosis was confirmed by a nick-end labeling method (19).

The animals were killed by decapitation, their hearts were removed rapidly, and blood was immediately collected from the abdominal aorta in nonheparinized tubes at the time of 15 and $20 \mathrm{mg} / \mathrm{kg}$ of cumulative dose of ADR. Heart tissues were removed and immediately frozen at $-70^{\circ} \mathrm{C}$ for enzyme analysis. Serum was separated from the blood immediately by centrifugation and used for determination of total and free CARN and acylcarnitine. All assays were performed in duplicate.
Enzyme assay for CPT I and II. Ten to twenty milligrams of frozen tissue was thawed, minced with razor blades, and homogenized with a Dounce homogenizer in $2 \mathrm{~mL}$ of buffer containing $150 \mathrm{mM}$ and $5 \mathrm{mM}$ Tris (pH 7.2) for CPT enzyme assay.

$\left[{ }^{14} \mathrm{C}\right]$ Carnitine was purchased from ARC (St. Louis, MO, U.S.A.). All other reagents for the enzyme assay were from Sigma Chemical Co. (St. Louis, MO, U.S.A.).

CPT activity was assayed using a modification of a method previously described by Esser et al. (20). All experiments were performed in duplicate. Assay tubes contained $10 \mathrm{mg} / \mathrm{mL}$ BSA, essentially fatty acid free, $250 \mu \mathrm{M}$ glutathione, $4.4 \mathrm{mM}$ ATP, $500 \mu \mathrm{M} \mathrm{KCN}, 4.2 \mathrm{mM} \mathrm{MgCl} 2,100 \mu \mathrm{M}$ rotenone, $200 \mu \mathrm{M}$ CARN, $0.125 \mu \mathrm{Ci}\left[{ }^{14} \mathrm{C}\right]$ Carnitine, and $50 \mu \mathrm{M}$ palmitoyl $\mathrm{CoA}$ in a final volume (including tissue homogenate) of $1 \mathrm{~mL}$. Additionally, blank tubes contained $15 \mathrm{mM} \mathrm{KCl}$ and $1 \mathrm{~mL}$ of 1.2 $\mathrm{M} \mathrm{HCl}$, CPT I activity tubes contained $15 \mathrm{mM} \mathrm{KCl}$, and CPT II activity tubes contained $50 \mu \mathrm{M}$ malonyl CoA. Tissue homogenates were either untreated or treated with $1 \%$ n-octyl $\beta$-D-glucopyranoside, held on ice and vortexed every $10 \mathrm{~min}$ for $30 \mathrm{~min}$. The assay was started with the addition of $100 \mu \mathrm{L}$ of tissue homogenate, and the tubes were incubated at $30^{\circ} \mathrm{C}$ for $15 \mathrm{~min}$. The reaction was stopped with the addition of $1 \mathrm{~mL}$ of 1.2 $\mathrm{M} \mathrm{HCl}$ and $1 \mathrm{~mL}$ of 1-butanol, and the tubes were vortexed for $30 \mathrm{~s}$. The tubes were centrifuged, and $500 \mu \mathrm{L}$ of the butanol layer was removed to another tube and washed with $100 \mu \mathrm{L}$ of water. Two hundred microliters of the butanol layer was transferred to a scintillation tube and counted on a scintillation counter. The cell homogenate protein concentration was measured by the method of Lowry et al. (21). Activity was expressed as nanomoles of palmitoyl-carnitine formed per minute per milligram of protein.

Determination of plasma total and free CARN and acylcarnitine. We used the method of Takahashi et al. (22). In brief, the enzymatic reaction was carried out in an incubator (SEOKWANG Scientific Co, Seoul, South Korea) at $37^{\circ} \mathrm{C}$ in a $10-\mathrm{cm}$ path length cuvette containing $1 \mathrm{~mL}$ of $100 \mathrm{mM}$ Tris-HCL, $\mathrm{pH}$ 9.5, $5 \mathrm{mM}$ thio-NAD, $0.2 \mathrm{mM} \mathrm{NADH}$, and 100 units of CARN dehydrogenase. The cuvette was incubated for $3 \mathrm{~min}$, after which the reaction was started with the addition of $50 \mu \mathrm{L}$ of plasma. A standard curve was constructed by the addition of CARN standards. After a 1-min delay, the absorbance increase was measured for $5 \mathrm{~min}$, and the rate was compared with the standard curve.

Statistical analysis. The data are expressed as the mean \pm SD of duplicate experiments. Statistical significance was determined using the unpaired $t$ test and analysis of variance. Unpaired $t$ test was used to determine statistical differences among groups ( $p<0.05$ was considered significant).

\section{RESULTS}

\section{Effect of CARN on CPT activity in ADR-treated rat heart.} Figure 1 shows the effect of CARN on heart tissue CPT I and CPT II activity at different doses in ADR-treated rat with and without CARN (Tables 1 and 2). After attaining a cumulative dose of $15 \mathrm{mg}$ (Table 1) and $20 \mathrm{mg}$ (Table 2), ADR caused a significant inhibition of the activity of heart CPT I and CPT II. ADR induced a $44 \%$ decrease of CPT I and a 32\% decrease of CPT II at a cumulative dose of $15 \mathrm{mg}$ (Table 1). There was a 


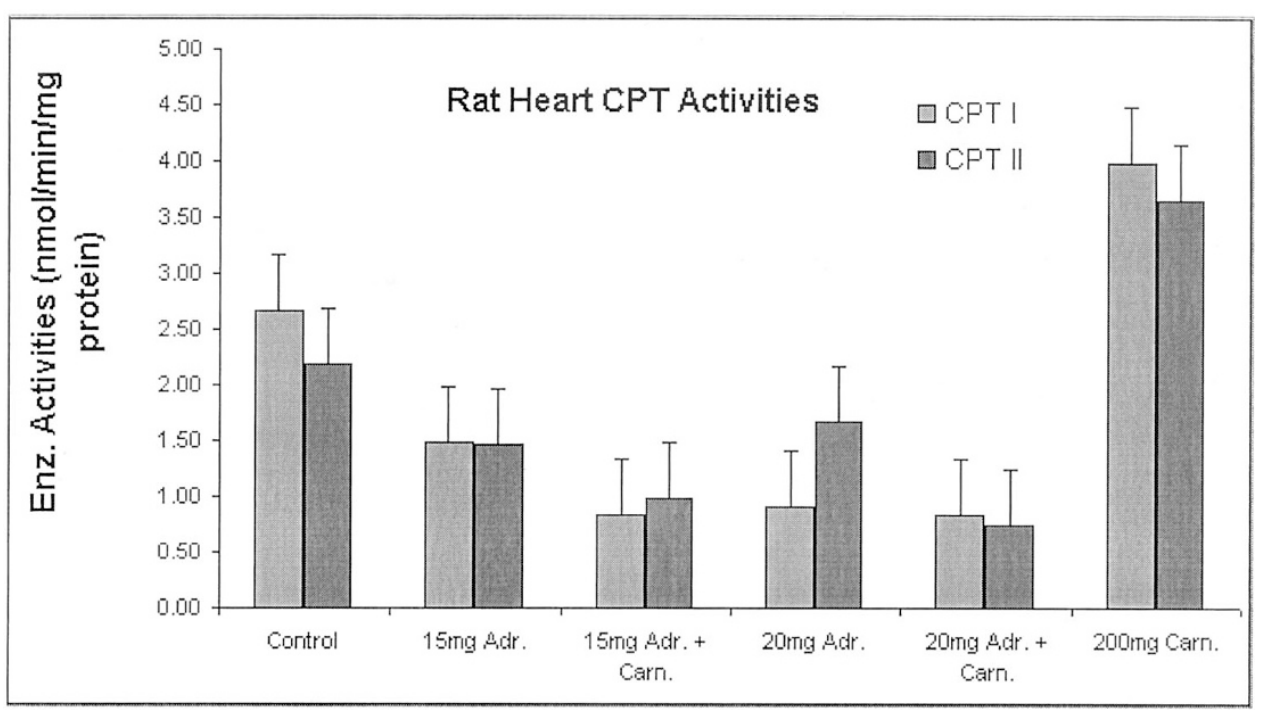

Figure 1. The effect of CARN on heart tissue CPT I and CPT II activity in ADR-treated rat with and without CARN. Results (mean \pm SD) are expressed as nanomoles per minute per milligram of protein. Numbers of rat included were two for control and CARN-treated rats and three for ADR- and ADR with CARN-treated rats. Heart tissue homogenates were incubated with CARN $(200 \mathrm{mg})$ for $30^{\circ} \mathrm{C}$ for $15 \mathrm{~min}$. Concentration of palmitoyl CoA were $200 \mu \mathrm{M}$. For detail refer to the enzyme assay in "Methods."

Table 1. CPT activity of ADR-treated rats with heart tissue presentations at a cumulative dose of $15 \mathrm{mg} / \mathrm{kg}$ of $A D R$

\begin{tabular}{lccc}
\hline \multicolumn{1}{c}{ Groups } & $\begin{array}{c}\text { CPT I } \\
(n=2)\end{array}$ & $\begin{array}{c}\text { CPT II } \\
(n=2)\end{array}$ & CPT I/CPT II \\
\hline Control $(n=2)$ & $2.7 \pm 2.2$ & $2.2 \pm 1.3$ & $1.1 \pm 0.4$ \\
ADR $(n=3)$ & $1.49 \pm 0.53 *$ & $1.46 \pm 0.72 *$ & $1.06 \pm 0.16$ \\
ADR + CARN $(n=3)$ & $0.84 \pm 0.12 *$ & $0.98 \pm 0.26^{*}$ & $0.85 \pm 0.26$ \\
CARN $(n=2)$ & $3.99 \pm 4.11^{*}$ & $3.64 \pm 3.18^{*}$ & $0.93 \pm 0.32$ \\
\hline
\end{tabular}

$* p<0.05$; significantly different from control group. Results (mean $\pm \mathrm{SD}$ ) are expressed as nanomoles per minute per milligram of protein. CPT activities were measured in duplicate $(n=2), n=$ number of independent experiments. $\mathrm{ADR}$, cumulative dose of $15 \mathrm{mg} / \mathrm{kg}$ of adriamycin-treated group; ADR + CARN, adriamycin and $200 \mathrm{mg} / \mathrm{kg}$ of L-carnitine-treated group; CARN, 200 $\mathrm{mg} / \mathrm{kg}$ of L-carnitine-treated group.

Table 2. CPT activity of ADR-treated rats with heart tissue presentations at a cumulative dose of $20 \mathrm{mg} / \mathrm{kg}$ of $A D R$

\begin{tabular}{lccc}
\hline \multicolumn{1}{c}{ Groups } & $\begin{array}{c}\text { CPT I } \\
(n=2)\end{array}$ & $\begin{array}{c}\text { CPT II } \\
(n=2)\end{array}$ & CPT I/CPT II \\
\hline Control $(n=2)$ & $2.7 \pm 2.2$ & $2.2 \pm 1.3$ & $1.1 \pm 0.4$ \\
ADR $(n=3)$ & $0.91 \pm 0.43^{*}$ & $1.66 \pm 0.88^{*}$ & $0.56 \pm 0.04 *$ \\
ADR + CARN $(n=3)$ & $0.83 \pm 0.22^{*}$ & $0.74 \pm 0.16^{*}$ & $1.13 \pm 0.24$ \\
CARN $(n=2)$ & $3.99 \pm 4.11 *$ & $3.64 \pm 3.18^{*}$ & $0.93 \pm 0.32$ \\
\hline
\end{tabular}

$* p<0.05$; significantly different from control group. Results (mean $\pm \mathrm{SD}$ ) are expressed as nanomoles per minute per milligram of protein. CPT activities were measured in duplicate $(n=2), n=$ number of independent experiments. ADR, cumulative dose of $20 \mathrm{mg} / \mathrm{kg}$ of adriamycin-treated group; ADR + CARN, adriamycin and $200 \mathrm{mg} / \mathrm{kg}$ of L-carnitine-treated group; CARN, 200 $\mathrm{mg} / \mathrm{kg}$ of L-carnitine-treated group.

$67 \%$ decrease of CPT I and a $23 \%$ decrease of CPT II at a cumulative dose of $20 \mathrm{mg}$ (Table 2).

The addition of CARN did not reverse the ADR-induced inhibition of CPT I and CPT II activity. Surprisingly, the activities of both CPT I and CPT II were further decreased when CARN was supplemented to the ADR. However, in rats supplemented with CARN alone, the activities of both CPT I and CPT II were significantly elevated, being 48 and $65 \%$ greater than the control rats (Tables 1 and 2, and Fig. 1).
Effect of CARN on the CARN level in ADR-treated rat plasma. Tables 3 and 4 show the effect of ADR treatment with and without CARN supplementation on the plasma CARN levels in ADR-treated rats. ADR caused a significant elevation of total and free CARN and acylcarnitine in plasma in a timeand dose-dependent manner. The free CARN concentration was significantly elevated in plasma $2 \mathrm{wk}$ after administration of ADR. The addition of CARN further increased the levels of total and free CARN and acylcarnitines. Administration of CARN alone $(200 \mathrm{mg})$ resulted in increased total and free CARN and acylcarnitines in plasma but at levels significantly lower than ADR plus CARN.

\section{DISCUSSION}

Although abnormalities of CPT activity and mitochondrial fatty acid oxidation have been associated with ADR use, the exact site of ADR inhibition remains to be determined. The inhibition of fatty acid oxidation by ADR may be at one or more sites in the pathway, including transport of fatty acids across the plasma membrane, activation in the cytosol by acyl-CoA synthetase, transport across the inner mitochondrial membrane via the CPT system, CPT 1, CARN-acylcarnitine

Table 3. Effect of carnitine on ADR-treated rats with plasma at a cumulative dose of $15 \mathrm{mg} / \mathrm{kg}$ of $A D R$

\begin{tabular}{lccc}
\hline \multicolumn{1}{c}{ Groups } & $\mathrm{TC}(n=2)$ & $\mathrm{FC}(n=2)$ & $\mathrm{AC}(n=2)$ \\
\hline Control $(n=4)$ & $38.3 \pm 5.9$ & $31.3 \pm 3.4$ & $7.0 \pm 3.5$ \\
ADR $(n=4)$ & $55.7 \pm 2.1^{*}$ & $22.3 \pm 5.2$ & $33.4 \pm 7.4^{*}$ \\
ADR + CARN $(n=4)$ & $325.3 \pm 54.4^{*}$ & $190.0 \pm 43.9^{*}$ & $135.4 \pm 20.1^{*}$ \\
CARN $(n=4)$ & $172.4 \pm 12.3^{*}$ & $120.8 \pm 7.9^{*}$ & $51.6 \pm 7.2$ \\
\hline
\end{tabular}

$* p<0.05$; significantly different from control group. Results (mean $\pm \mathrm{SD}$ ) are expressed as $\mu \mathrm{M}$. TC, total carnitine; FC, free carnitine; AC, acylcarnitine. Plasma TC, FC, and AC levels were measured in duplicate $(n=2), n=$ number of independent experiments. ADR, cumulative dose of $15 \mathrm{mg} / \mathrm{kg}$ of adriamycin-treated group; ADR + CARN, adriamycin and $200 \mathrm{mg} / \mathrm{kg}$ of L-carnitine-treated group; CARN, $200 \mathrm{mg} / \mathrm{kg}$ of L-carnitine-treated group. 
Table 4. Effect of carnitine on ADR-treated rats with plasma at a cumulative dose of $20 \mathrm{mg} / \mathrm{kg}$ of $A D R$

\begin{tabular}{lclc}
\hline \multicolumn{1}{c}{ Groups } & TC $(n=2)$ & FC $(n=2)$ & AC $(n=2)$ \\
\hline Control $(n=4)$ & $36.6 \pm 9.3$ & $27.2 \pm 1.8$ & $9.3 \pm 0.9$ \\
ADR $(n=4)$ & $98.9 \pm 40.4^{*}$ & $52.4 \pm 28.4^{*}$ & $46.5 \pm 15.7^{*}$ \\
ADR + CARN $(n=4)$ & $610.0 \pm 24.4^{*}$ & $381.2 \pm 33.8^{*}$ & $228.8 \pm 34.2^{*}$ \\
CARN $(n=4)$ & $180.1 \pm 13.7^{*}$ & $134.8 \pm 7.6^{*}$ & $45.2 \pm 6.1^{*}$ \\
\hline
\end{tabular}

$* p<0.05$; significantly different from control group. Results (mean $\pm \mathrm{SD}$ ) are expressed as $\mu \mathrm{M}$. TC, total carnitine; FC, free carnitine, AC, acylcarnitine. Plasma TC, FC, and AC levels were measured in duplicate $(n=2), n=$ number of independent experiments. ADR, cumulative dose of $20 \mathrm{mg} / \mathrm{kg}$ of adriamycin-treated group; ADR + CARN, adriamycin and $200 \mathrm{mg} / \mathrm{kg}$ of L-carnitine-treated group; CARN, $200 \mathrm{mg} / \mathrm{kg}$ of L-carnitine-treated group.

translocase, CPT II, and finally the oxidation in the mitochondrial matrix through the $\beta$-oxidation cycle. One study suggested that ADR may exert at least a part of its cardiotoxic effect by inhibiting the activity of CPT I, the rate-limiting step for mitochondrial transport, but not CPT II (17). A second study suggested that ADR inhibited both CPTs, suggesting a more global inhibition of the fatty acid oxidation process for which our data provide strongly supporting evidence (18).

In a previous study, we provided preliminary evidence that the administration of ADR resulted in inhibition of fatty acid oxidation (14). We demonstrated that plasma FFA levels were significantly higher in ADR-treated rats compared with control rats. In that study, long-chain fatty acids including palmitate $\left(\mathrm{C}_{16: 0}\right)$, linoleate $\left(\mathrm{C}_{18: 2}\right)$, oleate $\left(\mathrm{C}_{18: 1}\right)$, and stearate $\left(\mathrm{C}_{18: 0}\right)$ were significantly elevated, and it was speculated that this may result from impairment of long-chain fatty acid oxidation (14).

In the present study, both CPT I and CPT II activities were significantly decreased by ADR from 23 to $67 \%$ when compared with control rats, indicating a more generalized inhibition of fatty acid transport, or oxidation rather than inhibition of a specific target enzyme. This is consistent with the data presented by Kashfi et al. (18), who demonstrated inhibition of both CPT I and CPT II by ADR in isolated heart and liver mitochondria. The ratio of CPT I/CPT II in our study was 1.1 for control rats whereas that of CPT I/CPT II for ADR-induced cardiopathic rats was 1.06 after injection of $15 \mathrm{mg} / \mathrm{kg}$ of ADR (Table 1), and 0.56 after administration of $20 \mathrm{mg} / \mathrm{kg}$ of ADR (Table 2). This indicates that the activity of CPT I is more dramatically inhibited than CPT II at the highest dose of ADR (Tables 1 and 2). Our results showed that inhibition of CPT I by ADR was more sensitive than CPT II, similar to the findings reported by Kashfi et al. (18). These authors reported that the sensitivity of the outer membrane CPT to inhibition by ADR was greater than that of the inner membrane enzyme. The difference in that report could be a result of the way in which the inner membranes were prepared. ADR binds to the protein component rather than the lipid component of the membrane. It was suggested that inhibition by ADR is dependent on specific binding to the CPT protein, which appears to differ for the two enzymes only at the highest concentrations of ADR.

Our results contrast those of Brady and Brady (17), who suggested that CPT I was less sensitive to inhibition by ADR than CPT II and speculated that this was because of the lower cardiolipin in the outer mitochondrial membrane than the inner one. Brady and Brady (17) also demonstrated the interaction of
ADR with cardiolipin, the structural phospholipid of the inner mitochondrial membrane, forming an ADR-cardiolipin complex. It was suggested that this complex decreases the integrity of the inner mitochondrial membrane with the consequent decrease in the transport of long-chain acylcarnitine species. This hypothesis does not explain the clear inhibition of CPT II activity demonstrated in our study and the study of Kashfi et al. (18). Therefore, the precise mechanism of enzymic inhibition remains to be explained and will form the basis of our ongoing studies.

CARN is mostly derived from the diet, but is also synthesized de novo in the liver. It is concentrated in the myocytes to levels 20-50 times greater than those in plasma (23). High myocardial CARN levels are maintained by the action of a specific energy-dependent carnitine transporter, OCTN2. CARN promotes fatty acid oxidation by translocating activated long-chain fatty acids into the matrix of mitochondria as their acylcarnitine species. CARN deficiency result from genetic and environmental causes and may be associated with symptoms of metabolic disease, including hepatic dysfunction, skeletal myopathy, and cardiomyopathy (23-26). Primary CARN deficiency has been identified as a result of inherited defects of the plasma membrane CARN transporter. This disorder results in a progressive cardiomyopathy of infancy that is responsive to pharmacologic doses of CARN (23). Secondary CARN deficiency may result from other genetic diseases, dietary deficiency, chronic malabsorption, renal tubular dysfunction, hemodialysis, or peritoneal dialysis (27).

Fatty acid oxidation is the primary energy-providing pathway of the myocardium. Inhibition of the pathway as a result of primary or secondary causes of CARN deficiency has been shown to impair myocardial function $(10-12,14,15,23,27$, 28). Decreased myocardial levels of free CARN are thought to be part of the mechanism involved in the progression of heart failure (27-29).

In general, the CARN content of oxidative tissue (heart, 1.26 $\mu \mathrm{mol} / \mathrm{g}$ wet weight; liver, $0.94 \mu \mathrm{mol} / \mathrm{g}$ wet weight; skeletal muscle, $25.6 \mu \mathrm{mol} / \mathrm{g}$ noncollagenous protein) is much greater than that in plasma (approximately $50 \mathrm{nmol} / \mathrm{mL}$ ). The method for CARN measurement that we applied provides several advantages over traditional radioisotope exchange assays; in particular, it does not require radioisotope handling and is easily applicable to the clinical laboratory. To determine the presence of interfering compounds using our method, the concentration of free CARN was cross-checked by quantification using the gold standard assay of electrospray tandem mass spectrometry (30). Potential interference may be related to the presence of nonphysiologic acylcarnitines, such as valproylcarnitine (31) or pivaloylcarnitine (32). We did not find evidence for any interfering compounds potentially derived from ADR.

\section{CONCLUSIONS}

In conclusion, we observed that ADR appears to have a global effect on fatty acid transport with a profound inhibition of both CPT I and CPT II activities rather than specifically targeting one of these enzymes. The inhibition was not affected 
by CARN supplementation although CARN alone resulted in increased activity of both enzymes.

ADR also caused significant elevations of plasma total and free CARN and acylcarnitines. The mechanism for the high serum CARN fractions is unclear but may be caused by leakage or impaired uptake of myocardial CARN by the CARN transporter. Our ongoing studies will attempt to define the mechanisms of plasma CARN elevation and CPT inhibition in the ADR toxicity process.

\section{REFERENCES}

1. Singal PK, Siveski-Iliskovic N, Hill M, Thomas PT, Li T 1995 Combination therapy with probucol prevents adriamycin-induced cardiomyopathy. J Mol Cell Cardiol 27:1055-1063

2. Link G, Tirosh R, Pinson A, Hershko C 1996 Role of iron in the potentiation of anthracycline cardiotoxicity: identification of heart cell mitochondria as a major site of iron-anthracycline interaction. J Lab Clin Med 27:272-278

3. Doroshow JH 1983 Effect of anthracycline antibiotics on oxygen radical formation in rat heart. Cancer Res 43:460-472

4. Rajagopalan S, Politi PM, Sinha BK, Meyers CE 1988 Adriamycin-induced free radical formation in the perfused rat heart: implications for cardiotoxicity. Cancer Res 48:4766-4769

5. Mimnaugh EG, Trush MA, Gram TE 1983 Enhancement of rat heart microsomal lipid peroxidation following doxorubicin treatment in vivo. Cancer Treat Rep 67:731-733

6. Lampidis TJ, Johnson LV, Israel M 1981 Effects of adriamycin on rat heart cells in culture: increased accumulation and nucleoli fragmentation in cardiac muscle $\mathrm{v}$. non-muscle cells. J Mol Cell Cardiol 13:913-924

7. Torti SV, Akimoto H, Lin K, Billingham ME, Torti FM 1998 Selective inhibition of muscle gene expression by oxidative stress in cardiac cells. J Mol Cell Cardiol 30:1173-1180

8. Arai M, Tomaru K, Takizaua T, Sekiguchi K, Yokoyama T, Suzuki T, Nagai R 1998 Sarcoplasmic reticulum genes are selectively down-regulated in cardiomyopathy produced by doxorubucin in rabbits. J Mol Cell Cardiol 30:243-254

9. 1liskovic N, Singal PK 1997 Lipid lowering: an important factor in preventing adriamycin-induced heart failure. Am J Pathol 150:727-734

10. Abdel-aleem S, El-Merzabani MM, Sayed-Ahmed M, Taylor DA, Lowe JE 1997 Acute and chronic effects of adriamycin on fatty acid oxidation in isolated cardiac myocytes. J Mol Cell Cardiol 29:789-797

11. Iliskovic N, Li T, Khaper N, Palace V, Singal PK 1998 Modulation of adriamycininduced changes in serum free fatty acids, albumin and cardiac oxidative stress. Mol Cell Biochem 188:161-166

12. Bordoni A, Baigi PL, Hrelia S 1999 The impairment of essential fatty acid metabolism as a key factor in doxorubicin-induced damage in cultured rat cardiomyocytes. Biochim Biophys Acta 1440:100-106

13. Sayed-Ahmed MM, Sharawy S, Shouman SA, Osman AM 1999 Reversal of doxorubicin-induced cardiac metabolic damage by L-carnitine. Phamacol Res 39:289-295
14. Hong YM, Kim HS, Yoon HR 2002 Serum lipid and fatty acid profiles in adriamycininduced cardiomyopathy after administration of L-carnitine. Pediatr Res 51:249-255

15. Bressler R, Gay R, Copeland JG, Bahl JJ, Bedotto J, Goldman S 1989 Chronic inhibition of fatty acid oxidation: new model of diastolic dysfunction. Life Sci 44:1897-1906

16. Corr PB, Gross RW, Sobel BE 1984 Amphipathic metabolites and membrane dysfunction in ischemic myocardium. Circ Res 55:135-154

17. Brady LJ, Brady PS 1987 Hepatic and cardiac carnitine palmitoyltransferase activity: effects of adriamycin and galactosamine. Biochem Pharmacol 36:3419-3423

18. Kashfi K, Israel M, Sweatman TW, Seshadri R, Cook GA 1990 Inhibition of mitochondrial carnitine palmitoyltransferases by adriamycin and adriamycin analogues. Biochem Pharmacol 40:1441-1448

19. Hong YM, Kim SS 1998 The role of apoptosis in adriamycin induced cardiotoxicity and preventive effect of L-carnitine in rat. J Korean Pediatr Soc 41:760-768

20. Esser V, Brown NF, Cowan AT, Foster DW, McGarry JD 1996 Expression of a cDNA isolated from rat brown adipose tissue and heart identifies the product as the muscle isoform of carnitine palmitoyltransferase I (M-CPT I). J Biol Chem 271:6972-6977

21. Lowry OH, Rosebrough NJ, Farr A, Randall RJ 1951 Protein measurement with the Folin phenol reagent. J Biol Chem 193:265-275

22. Takahashi M, Ueda S, Misaki H, Sugiyama N, Matsumoto K, Matsuo N, Murao S 1994 Carnitine determination by an enzymatic cycling method with carnitine dehydrogenase. Clin Chem 40:817-821

23. Winter SC, Bruist NRM 2000 The role of energy metabolism defects in cardiomyopathy: from inborn errors to ischemia - cardiomyopathy in childhood, mitochondrial dysfunction, and the role of L-carnitine. Am Heart J 139:63-69

24. Treem WR, Stanley CA, Finegold DN, Hale DE, Coates PM 1988 Primary carnitine deficiency due to a failure of carnitine transport in kidney, muscle, and fibroblasts. N Engl J Med 319:1331-1336

25. Winter SC, Szabo-Aczel S, Curry CJR, Hutchinson HT, Hogue R, Shug AL 1987 Plasma carnitine deficiency: clinical observations in 51 pediatric patients. Am J Dis Child 141:660-665

26. Regitz V, Shug AL, Fleck E 1990 Defective myocardial carnitine metabolism in congestive heart failure secondary to dilated cardiomyopathy and to coronary, hypertensive and valvular heart disease. Am J Cardiol 65:755-760

27. Kawasaki N, Lee JD, Shimizu H, Ishii Y, Ueda T 1996 Cardiac energy metabolism stages of adriamycin-induced heart failure in rats. Int J Cardiol 55:217-225

28. Waber LJ, Valle D, Neill C, DiMauro S Shug A 1982 Carnitine deficiency presenting as familial cardiomyopathy: a treatable defect in carnitine transport. J Pediatr 101:700-708

29. Strauss M, Anselmi G, Hermoso T, Tejero F 1998 Carnitine promotes heat shock protein synthesis in adriamycin-induced cardiomyopathy in a neonatal rat experimental model. J Mol Cell Cardiol 30:2319-2325

30. Millington DS, Roe CR, Maltby DA 1984 Application of high resolution fast atom bombardment and constant $\mathrm{B} / \mathrm{E}$ ratio linked scanning to the identification and analysis of acylcarnitines in metabolic disease. Biomed Mass Spectrom 11:236-241

31. Millington DS, Bohan TP, Roe CR, Yergey AL, Liberato DJ 1985 Valproylcarnitine: a novel drug metabolite identified by fast atom bombardment and thermospray liquid chromatography-mass spectrometry. Clin Chim Acta 15:145:69-76

32. Vickers S, Duncan CA, White SD, Ramjit HG, Smith JL, Walker RW, Flynn H, Arison BH 1985 Carnitine and glucuronic acid conjugates of pivalic acid. Xenobiotica 15:453-458 